Elsevier Editorial System(tm) for Journal of Pharmaceutical and Biomedical Analysis

Manuscript Draft

Manuscript Number: JPBA-D-15-01580R1

Title: Simultaneous Determination of Domperidone and Itopride in Pharmaceuticals and Human plasma using RP-HPLC/UV Detection: Method Development, Validation and Application of the Method in In-vivo Evaluation of Fast Dispersible Tablets

Article Type: Full Length Article

Keywords: Domperidone

Itopride

ICH Guide lines

In-vivo Evaluation

RP-HPLC

Corresponding Author: Dr. Amjad Khan, Pharm-D., Ph.D.

Corresponding Author's Institution: Peshawar University

First Author: Amjad Khan, Pharm-D., Ph.D.

Order of Authors: Amjad Khan, Pharm-D., Ph.D.; Zafar Iqbal, B. Pharm, M. Pharm, PhD, Post Doc; Ibrahim Khadra, PhD; Lateef Ahmad, Pharm-D, PhD; Abad Khan; Muhammad Imran Khan; Zia Ullah; Ismail Ismail

Abstract: Domperidone and Itopride are pro-kinetic agents, regulating the gastric motility and are commonly prescribed as anti emetic drugs. In the present study a simple, rapid and sensitive RP-HPLC/UV method was developed for simultaneous determination of Domperidone and Itopride in pharmaceutical samples and human plasma, using Tenofavir as internal standard. Experimental conditions were optimized and method was validated according to the standard guidelines. Combination of water (pH 3.0 ) and acetonitrile $(65: 35 \mathrm{v} / \mathrm{v})$ was used as mobile phase, pumped at the flow rate of $1.5 \mathrm{ml} / \mathrm{min}$. Detector wavelength was set at $210 \mathrm{~nm}$ and column oven temperature was 40oc. Unlike conventional liquid-liquid extraction, simple precipitation technique was applied for drug extraction from human plasma using acetonitrile for deprotienation.

The method showed adequate separation of both the analytes and best resolution was achieved using Hypersil BDS C8 column (150mm x 4.6mm, $5 \mu \mathrm{m})$. The method was quite linear in the range of 20 - 600 ng/ml. Recovery of the method was 92.31\% and 89.82\% for Domperidone and Itopride, respectively. Retention time of both the analytes and internal standard was below 15min. The lower limit of detection (LLOD) and lower limit of quantification (LLOQ) for Domperidone were 5 and $10 \mathrm{ng} / \mathrm{ml}$ while for Itopride was 12 and $15 \mathrm{ng} / \mathrm{ml}$, respectively.

The developed method was successfully applied for in-vivo analysis of fast dispersible tablets of Domperidone in healthy human volunteer. The proposed method was a part of formulation development study and was efficiently applied for determination of the two drugs in various pharmaceutical products and human plasma. 


\section{Optimization of Experimental Conditions}

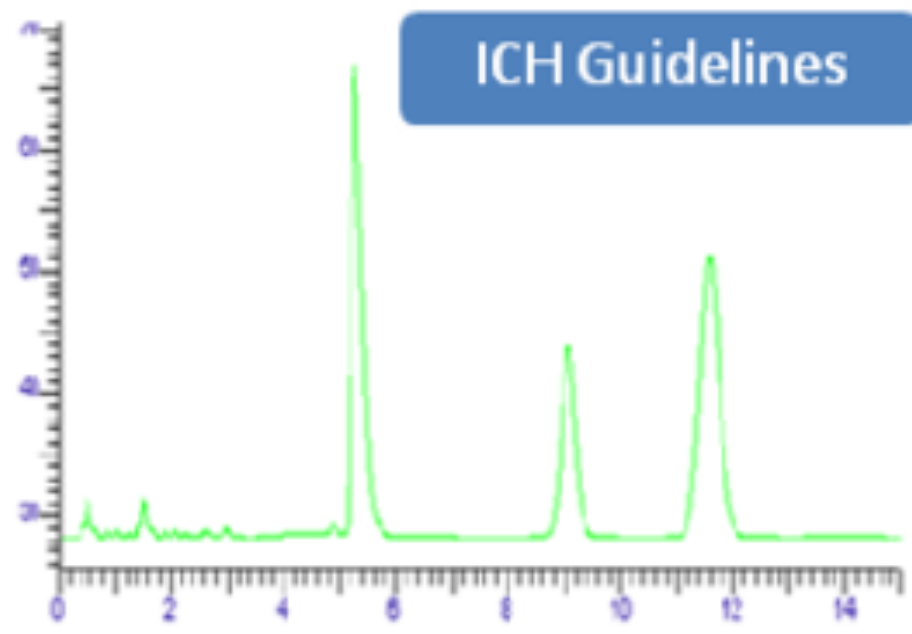

Drug Extraction from Human Plasma

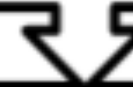

Development ofRP-HPLC Method of Analysis

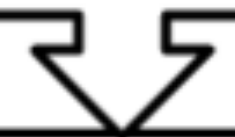

Validation of the Developed Method of Analysis

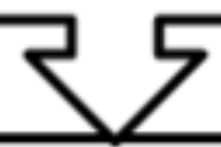

Application of the RP-HPLC Method of Analysis 


\section{Simultaneous Determination of Domperidone and Itopride in Pharmaceuticals and Human plasma using RP-HPLC/UV Detection: Method Development, Validation and Application of the Method in In-vivo Evaluation of Fast Dispersible Tablets}

Amjad Khan, Zafar Iqbal, Ibrahim Khadra, Lateef Ahmad, Muhammad Imran Khan, Abad Khan, Zia Ullah, Ismail.

\section{Highlights:}

$>$ Development and validation of method for simultaneous determination of Domperidone and Itopride in pharmaceuticals and human plasma

$>$ Application of the developed method for in-vivo evaluation of fast dispersible tablets of Domperidone

$>$ The developed method has simple mobile phase composition, shorter analysis time and was successfully applied for analysis of Domperidone and Itopride in pharmaceuticals and biological fluids (human plasma) 
1 Simultaneous Determination of Domperidone and Itopride in Pharmaceuticals

2 and Human Plasma using RP-HPLC/UV Detection: Method Development,

3 Validation and Application of the Method in In-vivo Evaluation of Fast

4 Dispersible Tablets

5

6 Amjad Khana, Zafar Iqbalb $₫$, Ibrahim Khadrac, Lateef Ahmadd, Abad Khand,

7 Muhammad Imran Khan', Zia Ullahb, Ismailb,

8 a Department of Pharmacy, Abasyn University, Peshawar-25120, Pakistan;

9 b Department of Pharmacy, University of Peshawar, Peshawar-25120, Pakistan;

10 cStrathclyde Institute of Pharmacy and Biomedical Sciences, Glasgow, UK.

11 d Department of Pharmacy, University of Swabi, Swabi, Pakistan; 


\section{Introduction}

Domperidone (6-chloro-3-[1-[3-(2-oxo-3H-benzimidazol-1-yl) propyl] piperidin-4-yl]-1H benzimidazol-2-one) is structurally related to butyrophenones having molecular formula of $\mathrm{C}_{22} \mathrm{H}_{24} \mathrm{ClN}_{5} \mathrm{O}_{2}$ and molecular weight of $425.91 \mathrm{~g} / \mathrm{mol}[1,2]$. It is a class-2 drug having $\mathrm{pH}$ dependent solubility. Experimental water solubility of Domperidone is $0.986 \mathrm{mg} / \mathrm{L}$ and its Pka value is 7.9 [3]. Domperidone is commonly prescribed as anti emetic with daily recommended dose of $10-40 \mathrm{mg}$ in divided doses.

8 Itopride (N-[[4-(2-dimethylaminoethoxy) phenyl] methyl]-3, 4-dimethoxy-benzamide $\mathrm{HCl})$ is a prokinetic agent. Chemically it is a substituted benzamide with molecular formula of $\mathrm{C}_{20} \mathrm{H}_{26} \mathrm{~N}_{2} \mathrm{O}_{4} \cdot \mathrm{HCl}$ and molecular weight of $394.89 \mathrm{~g} / \mathrm{mol}$ having $\mathrm{pKa}$ value of 8.72 [4, 5]. Physically it is a crystalline solid and freely water soluble. Recommended dose of Iopride for adult patients is $150 \mathrm{mg} /$ day in divided doses [6]. Structural formulae of Domperidone and Itopride are presented in Fig-1.

Both Domperidone and Itopride are prescribed for treatment of gastric esophageal reflux disorders (GERD) and are commonly used anti emetic [7]. Domperidone and Itopride regulate the gastric motility $[\mathbf{8}, \mathbf{9}]$ by;

$>$ Antagonizing inhibitory effect of dopamine at $\mathrm{D}_{2}$ receptors

$>$ Increasing stimulatory effect of acetylcholine by blocking its metabolizing enzyme acetylcholine esterase

To date several reversed phase high performance liquid chromatography (RP-HPLC) methods have been reported for analysis of Domperidone and Itopride. Most of the methods are applicable only for analysis of the drugs in various pharmaceutical dosage forms [10 - 19]. Due to lack of sensitivity, these methods cannot be applied for analysis of the drugs in biological samples. Few methods exhibited better sensitivity but involved derivatization technique and post column photochemical reactions [12]. In these methods drug was extracted from biological matrix using tedious and costly technique of solid phase extraction (SPE). In most of the reported methods, mobile phase composition is very complex, using buffer solutions as aqueous phase $[13,14,16]$.

It was required to develop a rapid, sensitive and simple method involving no derivatization or other advanced technique. The aim of the presented work was to develop a sensitive, rapid and simple RP-HPLC/UV method for simultaneous determination of Domperidone and Itopride in 
1 pharmaceutical and biological samples (human plasma). The suggested method is economical,

2 involves simple extraction procedure, requires lesser sample volume and possesses a shorter

3 chromatographic analysis run time as compared to other reported methods. The developed

4 method was successfully applied for in-vivo evaluation of fast dispersible tablets of

5 Domperidone in human volunteers.

\section{Experimental}

$8 \quad 2.1$ Chemicals and reagents

9 Domperidone (purity 99.9\%) was provided by Medicraft Pharmaceuticals, Peshawar, Pakistan, Itopride (purity 99.75\%) and Tenofovir were gifted by Ferozsons Laboratories Ltd. Nowshera, Pakistan. HPLC grade acetonitrile (purity 99.9\%), methanol (purity 99.9\%) and analytical grade ortho-phosphoric acid (OPA; purity 85\%) were purchased from Sigma-Aldrich (Oslo, Norway). Ultra pure HPLC grade water was prepared by Milli-Q® system (Millipore, Milford, MA, USA).

\subsection{Instrumentation}

Chromatographic analysis was performed using HPLC system equipped with an auto sampler, vacuum degasser, peltier column oven, pump, and UV-visible detector (Perkin Elmer Series 200 system, Norwalk, USA). The chromatographic data was analyzed on Perkin Elmer Total-chrom workstation software (version 6.3.1, Bridgeport, USA) linked with the LC-system through network chromatography interface (NCI) 900. Separation of the analytes was carried out using Hypersil BDS C8 column $(150 \mathrm{~mm} \times 4.6 \mathrm{~mm}, 5 \mu \mathrm{m})$ protected by a Perkin Elmer pre-column guard cartridge C18 $(30 \mathrm{~mm} \times 4.6 \mathrm{~mm}, 10 \mu \mathrm{m}$; Norwalk, USA).

\subsection{Optimization of chromatographic conditions}

Different mobile phases, consisting of acetonitrile, acidified water (pH adjusted to 3.0 with OPA; 35:65, v/v), methanol, acetonitrile and acidified water ( $\mathrm{pH}$ adjusted to 3.0 with OPA; 25:25:50 $\mathrm{v} / \mathrm{v})$ and methanol, acidified water $(25: 75, \mathrm{v} / \mathrm{v})$, pumped with different flow rates in the range of $0.5-2.0 \mathrm{ml} / \mathrm{min}$ in an isocratic mode were evaluated. Chromatographic analyses were performed

27 at different column oven temperatures in the range of $25-50{ }^{\circ} \mathrm{C}$. The injection volume was studied in the range of $10-50 \mu 1$.

\subsection{Preparation of standard solutions}

30 Stock solutions of Domperidone and Itopride and Tenofovir (concentration $=1.0 \mathrm{mg} / \mathrm{ml}$ ) were prepared in methanol and water, separately, on the basis of their respective solubility and stored 
1 at $-4^{\circ} \mathrm{C}$. Stock solutions were diluted with the mobile phase (acetonitrile: water, 35:65, v/v) to 2 obtain various dilutions in the range of $10-600 \mathrm{ng} / \mathrm{ml}$ (i.e., 10, 50, 100, 200, 400, 500 and $3600 \mathrm{ng} / \mathrm{ml})$.

\section{$4 \quad 2.5$ Sample preparation}

5 Stock solution of both analytes and internal standard were prepared separately in water and organic solvent (methanol), on the basis of their respective solubility. Stock solutions of Domperidone and internal standard (Tenofovir) were prepared in methanol while purified water was used for preparation of Itopride solution. Concentration of the stock solutions of all the compounds was $1 \mathrm{mg} / \mathrm{ml}$. Working solutions $(10 \mathrm{ml})$ of both analytes were prepared by dilution of stock solution with mobile phase on daily basis.

Blood samples (about 3ml) collected from healthy human volunteers in the ethylene diamine tetraacetic acid (EDTA) tubes were centrifuged at $4000 \times \mathrm{g}$ for $10 \mathrm{~min}$ at $4^{\circ} \mathrm{C}$ to separate plasma.

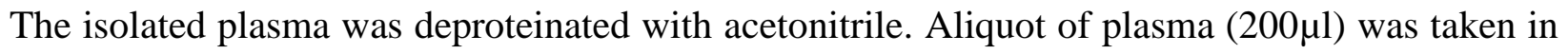
Eppendorf tube $($ capacity $=1 \mathrm{ml})$, acetonitrile $(600 \mu \mathrm{l})$ was added and vertexed for $2 \mathrm{~min}$. Sample was centrifuged at $4000 \mathrm{x}$ g for $10 \mathrm{~min}$ and supernatant was collected using posture pipette. The separated plasma was stored at $-20^{\circ} \mathrm{C}$ till further use.

17 On the day of analysis, plasma samples were thawed at room temperature and spiked with appropriate concentrations of working solutions to obtain calibration standards $\{$ in the range $10-$ $600 \mathrm{ng} / \mathrm{ml}$ (Domperidone) and $15-600 \mathrm{ng} / \mathrm{ml}$ (Itopride) $\}$. The calibration curves covered the maximum therapeutic concentrations achieved by both the drug in-vivo. The amount of stock solution in all spiked samples was kept below $2.0 \%$ of the total sample volume to minimize any systematic errors between real samples and standards.

\subsection{Sample collection and extraction}

24 Plasma samples $(200 \mu 1)$ were spiked with known amount of Domperidone, and Itopride, internal standard solution $(10 \mu \mathrm{l})$ was added and mixed for 10s. Unlike traditional liquid-liquid extraction, simple precipitation technique was applied for drug extraction from biological sample. That is

27 the sample was deproteinated with acetonitrile and diluted with mobile phase. Schematic presentation of extraction procedure is shown in Fig-2. 
2 The suggested method was validated according to standard guidelines [20 - 22] with emphasis on linearity, precision, specificity/selectivity, accuracy, sensitivity (lower limit of detection and

4 lower limit of quantification), sample stability, and robustness.

\section{$5 \quad$ 2.7.1 Linearity} each analyte to the area of internal standard was plotted against their corresponding concentration [23, 24] and slope (a), intercept (b) correlation coefficient (r) and covariance (\%RSD) were determined from the regression analysis using the least squares method.

\subsubsection{Precision}

Precision of the method was determined in terms of injection repeatability and analysis repeatability of spiked plasma samples. In order to determine injection repeatability, plasma samples spiked with $250 \mathrm{ng} / \mathrm{ml}$ each of Domperidone and Itopride were injected $(\mathrm{n}=5)$ into HPLC. Peak area and retention time of both the drugs were determined and results were expressed as mean and covariance (mean; \%RSD). Analysis repeatability was verified by determining the recovered amount from plasma samples spiked with known concentration of both drugs (Domperidone and Itopride). Results were presented as mean; \%RSD ( $n=5)$.

To determine intermediate precision (intra-day and inter day reproducibility), plasma samples spiked with different concentrations of Domperidone and Itopride were analyzed three times a day (at 8 hours interval) on day-1 (intraday). Inter day study was carried out by analyzing the same sample (spiked samples used in intraday study) on daily basis for next three days. The results were presented as mean \pm standard deviation; covariance $(n=5)$.

\subsubsection{Selectivity/specificity}

The specificity of the method was evaluated by verifying the complete separation of the peaks of

27 both the analytes and internal standard in standard solutions (solutions of both analytes prepared in mobile phase) and spiked plasma samples [23].

\subsubsection{Accuracy}

30 Percent recovery was used for determination of accuracy of the proposed method [24]. Percent 
1 concentrations $(100,250$ and $500 \mathrm{ng} / \mathrm{ml})$ of both the analytes. Concentration of internal standard

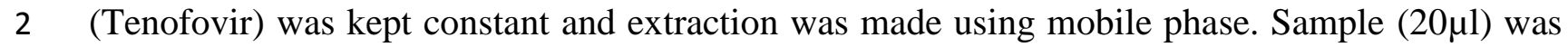

3 injected into the HPLC system in triplicate $(n=3)$ and percent recovery was calculated using

4 following equation;

5

$$
\% \text { Recovery }=[\mathrm{A} / \mathrm{B}] \times 100
$$
Eq-1

Where

$\mathrm{A}=$ Peak area response ratios of the analytes with reference to IS in the plasma samples

$\mathrm{B}=$ Peak area response ratios of the analytes with reference to IS mobile phase

Amount recovered from each sample was calculated using the following equation;

$$
\mathrm{C}=(\mathrm{X} / \mathrm{Y}) \times(\mathrm{A} / \mathrm{B}) \times \mathrm{Cs} \times \mathrm{F}_{\mathrm{D}}
$$

Where

$\mathrm{X}$ and $\mathrm{Y}=$ Peak areas of the analyte in plasma samples and 1:1 mixture, respectively $\mathrm{A}$ and $\mathrm{B}=$ Peak areas of the internal standard in 1:1 mixture and plasma samples, $\mathrm{Cs}=$ Concentration of analyte in the $1: 1$ mixture

$\mathrm{FD}=$ Dilution factor

Standard deviation (SD) and covariance (\%RSD) were calculated for each sample

\subsubsection{Sensitivity}

Sensitivity of the method was evaluated on the basis of determination of the lower limit of detection (LLOD) and lower limit of quantification (LLOQ) for both the analytes. Signal to noise ratio $(\mathrm{S} / \mathrm{N})$ was determined for each analyte using HPLC software. Lower limit of detection was the concentration at which signal to noise ratio was $3(\mathrm{~S} / \mathrm{N} \approx 3)$ and lower limit of quantification (LLOQ) was the concentration at which $\mathrm{S} / \mathrm{N}$ ratio was $10(\mathrm{~S} / \mathrm{N} \approx 10)$.

\subsubsection{Sample stability}


1 Stability of both the analytes was evaluated by keeping samples at various temperatures. Samples

2 of both the analytes were stored at room temperature and $-20{ }^{\circ} \mathrm{C}$ for one week and analyzed.

3 Percent stability and percent loss were calculated using the following equations [24, 25];

Where

$$
\begin{aligned}
& \mathrm{S}_{\mathrm{t}}=\text { Stability of analyte at time } \mathrm{t} \\
& \mathrm{S}_{0}=\text { Stability at initial time (stability of fresh solution) }
\end{aligned}
$$

\subsubsection{Robustness}

Robustness of the method was estimated by changing various experimental conditions and evaluating their effect on peak area, peak height and retention time of both the analytes. Small deliberate changes were made in different chromatographic condition like column oven temperature $\left( \pm 5^{\circ} \mathrm{C}\right)$, mobile phase composition, mobile phase flow rate $( \pm 0.2 \mathrm{ml} / \mathrm{min})$, detector wave length $( \pm 2 \mathrm{~nm})$ and detector voltage $( \pm 50 \mathrm{mV})$.

\subsection{Statistical interpretation and correlation of data}

Various statistical tools such as mean (X), standard deviation (SD) and relative standard deviation (\%RSD) were calculated using MS Excel and applied for quantification of both the analytes.

\subsection{Application of the method in pharmacokinetic evaluation of fast dispersible tablets of}

\section{Domperidone}

The method was transferred to the Biopharmaceutical Laboratory of the Department of Pharmacy, University of Peshawar, Pakistan. The method transfer was controlled by a procedure including development of a transfer plane, definition of transfer tests and acceptance criteria (sample analysis: sample time and replication, validation experiments), training of laboratory staff and full method validation. The method parameters were identical with regard to mobile phase composition, HPLC column, detector wavelength and extraction procedure. The HPLC system was different and minor modifications to the laboratory procedures had to be made in order to adapt it to the local conditions. The clinical application of the method was assessed by measuring Domperidone in plasma samples of healthy human volunteers (Pharmacy Graduates in the Department of Pharmacy, University of Peshawar). The study was conducted according to 
the guidelines of "World Medical Associations, Declaration of Helsinki-ethical principles for

2 medical research involving human subjects" and was approved by the institutional "Committee

3 for Research Ethics”, Department of Pharmacy, University of Peshawar, under license number

4 “UOP/PHARM-EC/387”.

5 Fast dispersible tablet of Domperidone was dispersed in a glass of water (200ml) and taken by

6 each volunteer. Blood samples $(3 \mathrm{ml})$ were obtained at specified time intervals $(0,5,15,30,60$,

$7120,180,240,300$ and 360min) following tablet administration. Blood samples were collected in

8 EDTA tubes and centrifuged at $4000 \mathrm{x}$ g for $10 \mathrm{~min}$ at $4{ }^{\circ} \mathrm{C}$ to separate the plasma.

9 Deproeination of plasma samples was carried out using acetonitrile. An aliquot of plasma $10(200 \mu 1)$, together with internal standard was taken in eppendorf tube, acetonitrile (3 times 11 volume of plasma sample) was added to it, vertexed for $2 \mathrm{~min}$ and centrifuged at $4000 \mathrm{x} \mathrm{g}$ for $125 \mathrm{~min}$. Supernatant was isolated in a separate eppendorf tube ( $1 \mathrm{ml}$ capacity), volume was made 13 up with mobile phase and vertexed for $1 \mathrm{~min}$. The plasma samples, isolated in separate eppendorf 14 tubes, were stored at $-20{ }^{\circ} \mathrm{C}$ till further analysis. On the day of analysis, the frozen samples were thawed at room temperature. The samples were analyzed in triplicate to ensure satisfactory method performance in accordance with the standard guidelines.

17 The plasma concentration of Domperidone in human plasma samples was quantified at various time intervals following oral administration of fast dispersible tablets. The data was fitted in the compartmental models to calculate various pharmacokinetic parameters such as $\mathrm{t}_{\max }, \mathrm{C}_{\max }$, Half life ( $\mathrm{t} 1 / 2)$ and area under cure (AUC). The pharmacokinetic data was assessed using Microsoft

21 Excel 2007 and PK-Summit®, a pharmacokinetics software.

\section{Results and Discussion}

Domperidone and Itopride were analyzed for first time simultaneously using Tenofavir as internal standard. Various experimental conditions were optimized and method was validated according to the ICH guidelines [22]. The proposed method was a rapid one and all the analytes were separated within $15 \mathrm{~min}$. Of the various analytical conditions studied, best results were

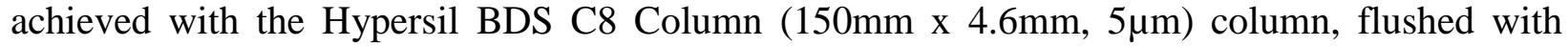
combination of acetonitrile and acidified water $(35: 65, \mathrm{v} / \mathrm{v})$ as the mobile phase, pumped at a flow rate of $1.5 \mathrm{ml} / \mathrm{min}$ at $40{ }^{\circ} \mathrm{C}$. 


\subsection{Sample preparation}

2 Methanol, acetonitrile and 1:1 mixture of methanol and acetonitrile were evaluated for protein precipitation; however better protein precipitation was achieved with acetonitrile. Volume of acetonitrile at least 3 times the volume of plasma was used for protein precipetation. 3.2 Optimization of analytical conditions and experimental parameters

Hypersil BDS C8 Column (150 x 4.6mm, $5 \mu \mathrm{m})$ column was used for separation of Domperidone and Itopride. Other columns like Discovery HS C18 column $(150 \mathrm{~mm} \times 4.6 \mathrm{~mm}, 5 \mu \mathrm{m})$, Symmetry C8 column $(150 \mathrm{~mm} \times 3.9 \mathrm{~mm}, 5 \mu \mathrm{m})$ and Symmetry C8 $(250 \mathrm{~mm} \times 4.6 \mathrm{~mm}, 5 \mu \mathrm{m})$ were also tried. With these peaks overlapping and broadening were observed for both analytes. Hypersil BDS C8 $(150 \mathrm{~mm} \times 4.6 \mathrm{~mm}, 5 \mu \mathrm{m})$ column was selected as the best on the basis of excellent peak parameters (retention, separation, tailing, asymmetry, and resolution) and shorter run time.

Different combinations of organic solvents (methanol and acetonitrile) and water were used as mobile phase. Water used in preparation of mobile phase was acidified (pH adjusted to 3) with ortho phosphoric acid (85\%) avoiding use of buffer solution. Different isocratic solvent systems, consisting of acetonitrile-acidified water (25:75, 35:65 and 50:50, v/v), methanol-acidified water (25:75 and 50:50, v/v) and methanol-acetonitrile-acidified water (25:25: 50, v/v) were assessed as the mobile phases. In comparison to methanol, acetonitrile resulted in better peak area and peak shape so acetonitrile was included as organic solvent in mobile phase. It was noticed that increase in ratio of acetonitrile in mobile phase decreased retention time of all the compounds resulting in shorter analysis time but peak area and peak height were significantly affected. Domperidone is water insoluble compound and by increasing ratio of acetonitrile in mobile phase resulted in increased sensitivity of the method for Domperidone. Similarly area of Itopride reduced with increasing quantity of acetonitrile in mobile phase. Combination of acetonitrile and acidified water (35: 65, v/v) resulted in the best results in terms of peak shape, area, retention time and resolution and was selected as mobile phase for further analysis. Mobile phase of different $\mathrm{pH}$ was prepared by changing $\mathrm{pH}$ of water in the range of $2-5$ with $O$-phosphoric acid. Sensitivity and retention time of all the compounds were significantly affected by $\mathrm{pH}$ of the mobile phase. At higher $\mathrm{pH}$ sensitivity of the method was reduced and retention time was increased for all the compounds. Effect of changes in $\mathrm{pH}$ was more prominent with Domperidone as its retention time was increased up to $20 \mathrm{~min}$ with very low sensitivity (Fig-3). At lower $\mathrm{pH}$ retention time decreased but separation between Domperidone and Itopride 
was also reduced significantly. Best peak shape with better resolution and sensitivity were

2 obtained at $\mathrm{pH} 3$ and was selected as optimum $\mathrm{pH}$ of mobile phase for further analysis.

3 Retention time, peak shape and peak area were significantly affected by flow rate of the mobile

4 phase. Best results were obtained at flow rate of $1.5 \mathrm{ml} / \mathrm{min}$ and selected as optimum flow rate for

5 further analysis.

6 Column oven temperature was studied in the range of $25-50{ }^{\circ} \mathrm{C}$ and best results were obtained

7 at $40{ }^{\circ} \mathrm{C}$. At higher column oven temperature, sensitivity of the method was increased with

8 improved peak height. Better peak shape and resolution were obtained at $40{ }^{\circ} \mathrm{C}$ and selected as

9 column oven temperature for simultaneous determination of the two drugs.

10 Internal standard was selected on the basis of its specificity, sensitivity, recovery and

11 compatibility with Domperidone and Itopride. Various compounds like Ciprofloxacin, Naproxin

12 Sodium, Tenofovir and Atenolol were tried as internal standard. Among them Tenofovir

13 exhibited better recovery and peak separation and was used as internal standard.

\section{$14 \quad 3.3$ Method validation}

15 The proposed method of analysis was validated according to standard guidelines in terms of selectivity, sensitivity, recovery, precision and robustness.

\section{$17 \quad$ 3.3.1 Specificity and selectivity}

18 The proposed method of analysis was highly selective and specific as peaks of both analytes and internal standard were well resolved. Separation of peaks was confirmed by using blank plasma, plasma spiked with both analytes and internal standard. The method is well suitable for analysis of Domperidone and Itopride in pharmaceutical solutions as well as biological samples.

\subsubsection{Linearity}

Linearity of the method was determined from calibration curve of the standard mixtures and spiked plasma samples. Calibration curves were constructed at seven concentration levels in the range of $10-600 \mathrm{ng} / \mathrm{ml}$ for Domperidone and $15-600 \mathrm{ng} / \mathrm{ml}$ for Itopride, separately for standard mixture and spiked plasma samples. Regression analysis of calibration curves of both drugs

27 showed that the method is quite linear within the said concentration range. Regression equation and correlation coefficient values of calibration curves of both the drugs are presented in Table1. 


\subsubsection{Accuracy of the method (percent recovery)}

2 Percent recovery from plasma was used for determination of accuracy of the proposed method.

Percent recovery was determined at three concentration levels $(100 \mathrm{ng} / \mathrm{ml}, 250 \mathrm{ng} / \mathrm{ml}$ and $500 \mathrm{ng} / \mathrm{ml}$ ) of both drugs and was found above $91 \%$ and $89 \%$ for Domperidone and Itopride,

5 respectively (Table-2).

\subsubsection{Precision of the method}

Precision of the method was evaluated on the basis of repeatability and intermediate precision. Intermediate precision was determined in terms of intra and inter day reproducibility. Results of analysis repeatability, inter day precision and intraday precision are presented in Table-2. There is complete harmony among repeated injections, repeated analysis, inter day and intraday study.

\subsubsection{Stability of Solutions}

Stability study was conducted at room temperature $\left(18-23{ }^{\circ} \mathrm{C}\right)$ and freezer temperature $\left(-20{ }^{\circ} \mathrm{C}\right)$ for one week. Both Domperidone and Itopride were stable during the freeze/thaw cycles and for at least $24 \mathrm{hr}$ in each step of the analysis. All the samples were stable at $-20{ }^{\circ} \mathrm{C}$ for the specified period. At room temperature Domperidone and internal standard (Tenofavir) remained stable while Itopride degraded to a significant level. The percent degradation of drugs in both spiked plasma samples and standard solutions stored at room temperature was higher as compared to the samples stored at $-20{ }^{\circ} \mathrm{C}$. It revealed that all the samples containing Itopride should be stored at $20{ }^{\circ} \mathrm{C}$ to avoid stability issue.

\subsubsection{Sensitivity (Limit of Detection and Lower Limit of Quantification)}

Lower limit of detection (LLOD) and lower limit of quantification (LLOQ) of the two drugs are quite low as presented in Table-1. Values of LLOD and LLOQ proved that the proposed method was more sensitive than the previously reported method for the drugs. Respective chromatograms of LLOD and LLOQ of both drugs are given in Fig-4.

\subsubsection{Robustness}

Minor deliberate changes in analytical parameters did not significantly affect retention times, percent recovery and peak area of both the drugs. Thus, the method was robust for minor changes in column oven temperature, i.e., $40 \pm 2{ }^{\circ} \mathrm{C}$, flow rate, i.e., $1.5 \pm 0.2 \mathrm{ml} / \mathrm{min}$ and $\mathrm{pH}$ of 


\section{4. Applicability of the method}

2 This method was a part of an extensive formulation development process involving in-vitro and in-vivo characterization of novel formulations of fast dispersible tablet of Domperidone and

4 Itopride. The developed method was successfully applied for in-vitro evaluation (drug excipients 5 compatibility study, determination of drug content and dissolution rate of compressed tablets; data not shown) and determination of pharmacokinetics of Domperidone in healthy human volunteers, following oral administration of fast dispersible tablets. The pharmacokinetics study 8 of fast dispersible tablets of Domperidone (10mg) was carried out in healthy human volunteers 9 (age range $=24-29$ years). The study was approved by the "Committee for Research Ethics" of Department of Pharmacy, University of Peshawar and written consent form was signed by each volunteer. Drug content of each sample was determined and pharmacokinetic parameters were calculated using pharmacokinetics software PK Summit. Applicability of the method is illustrated in Fig-5 showing mean plasma concentration versus time curve for Domperidone. Various pharmacokinetics parameters determined in healthy human 


\section{Acknowledgement}

2 We are thankful to Higher Education Commission of Pakistan for providing financial support to 3 carry out the study.

\section{References}

[1]. A.R. Parker, Domperidone, Pharma profile Compendium, (2001) 3.

[2]. D. Silvers, M.K., V. Broadstone, D. Patterson, E.M.M. Quigley, R. McCallum, N.K. Leidy, C. Farup, Y. Liy, A. Joslyn, , Domperidone in the Management of Symptoms of Diabetic Gastroparesis: Efficacy, Tolerability and Quality-of-Life Outcomes in a Multicenter Controlled Trial, Clin. Ther. 20 (1998) 3.

[3]. M.S. Nagarsenker, S.D. Garad, G. Ramprakash, Design, optimization and evaluation of domperidone coevaporates, J. Control. Release. 63 (2000) 31, 1 - 39.

[4]. A.M. Gupta, A.V. Belgawar, S.W. Prashant, R.P. Trivesh, D.R. Mundhada, Design and development of hydrodynamically balanced tablet of Itopride, J. Chem. Phar. Res. 3 (2011) 856 - 864.

[5]. J. Ma, L. Yuan., M. Ding, J. Zhang, Q. Zhang, Q. Xu, X. Zhou, Determination of itopride hydrochloride in human plasma by RP-HPLC with fluorescence detection and its use in bioequivalence study, Pharmacol. Res. 59 (2009) 189 - 193.

[6]. S. Gupta, V. Kapoor and B. Kapoor, Itopride: A Novel Prokinetic Agent, J. K. Science. 6 (2004) 2.

[7]. P. Sawant, H.S. Dass, N. Desai, S. Kalokhe, S Patil, Comparative Evaluation of the Efficacy and Tolerability of Itopride Hydrochloride and Domperidone in Patients with Non-ulcer Dyspepsia, J. A. P. I. 52 (2004).

[8]. W.Y. Gorge., The pharmacology of prokinetic agents and their role in the treatment of gastro intestinal disorders, I. J. G. E. 1 (2003) 4.

[9]. Y. Vandenplas, S. Salvatore, B. Hauser, The diagnosis and management of gastrooesophageal reflux in infants, Early Hum. Dev. 81 (2005) 1011 - 1024.

[10]. X. Wang, L. Jing, Q. Zhu, F. Li, Z. Xiong, Development and Validation of UPLCMS/MS Method for Determination of Domperidone in Human Plasma and its Pharmacokinetic Application, Biomed. Chromatogr. (2012) 
[11]. M. Kobylinska and K. Kobylinska, High Performance Liquid Chromatographic Analysis for the Determination of Domperidone in Human Plasma, J. Chromatogr. B. 744 (2000) $207-212$.

[12]. A.P. Argekar, S.J. Shah, Simultaneous determination of cinnarizine and domepiridone maleate from tablet dosage form by reverse phase ion pair high performance liquid chromatography, J. P. B. A. 19 (1999) 813 - 817.

[13]. M.S. Mondal, M.A. Haque, M.S. Islam, S.M.A. Islam, Development and Validation of RP-HPLC Method for the Simultaneous Estimation of Domperidone and Naproxen in Tablet Dosage Form, J. A. P. S. 1 (2011) 145 - 148.

[14]. B. Patel, Z. Dedania, R. Dedania, C. Ramolia, G.V. Sagar, R.S. Mehta, Simultaneous Estimation of Lansoprazole and Domperidone in Combined Dosage Form by RP-HPLC, Asian J. Res. Chem. 2 (2009) 2.

[15]. P.R. Battu, Simultaneous HPLC Estimation of Pantoprazole and Domperidone from Tablets, Int. J. Chem. Res. 1 (2009) 275 - 277.

[16]. K.R Gupta, R.B. Chawla, S.G. Wadodkar, Stability Indicating RP-HPLC Method for Simultaneous Determination of Pantaprozol Sodium and Itopride $\mathrm{HCl}$ in Bulk and Capsules, E. J. Chem. 2 (2010).

[17]. R.K. Patel, B.P. Raval, B.H. Patel, L.J. Patel, Reverse Phase High Performance Liquid Chromatographic method for the simultaneous estimation of Esomeprazole and Itopride in Capsule, Der. Pharma Chem. 2 (2010) 251 - 260.

[18]. S.H. Rasheed, M. Ramakotaiah, K. Ravikumar, C. Naghabushanam, C.M.M.P. Rao, Estimation of Rebaprazole Sodium and Itopride Hydrodrchloride in Tablet Dosage Form Using Reverse Phase High Performance Liquid Chromatograp, E. J. Chem. 8 (2011) 37 42.

[19]. D. Umamaheswari , M. Kumar, B. Jayakar, R. Chatakonda, Method develpopment and validation of Itopride Hydrochloride and Rabeprazple Sodium in pharmaceutical dosage form by Reversed Phase High Performance Liquid Chromatography, J. Chem. Pharm. Res. 2 (2010) 399 - 417.

[20]. Guide lines for the validation of analytical methods for active constituents, agricultural and veternity chemical products Australian Pesticides and Vaternary Medicine Authority, Editor. 2004: PO Box E240 Kingston 2604 Australia. 
1 [21]. Guidance for the Validation of Analytical Methodology and Calibration of Equipment used for Testing of Illicit Drugs in Seized Materials and Biological Specimens, U Nation Office on Drugs and Crimes, Laboratory and Scientific Section, Vienna, (2009) New York, USA.

[22]. European Medicine Agency, Note for guidance on validation of analytical procedures; Text and methodology in CPMP/ICH/381/95, (1995), Westferry Circus, Canary Wharf, London, E14 4HB, UK.

[23]. L. Huber, Validation of Analytical Methods. A Primer by Agilant Technologies.

[24]. L. Ahmad, Z. Iqbal., S. Nazir, Y. Shah, A. Khan, M. I. Khan, F. Nasir, A. Khan, Optimization and Validation of HPLC-UV method for simultaneus determination of Omeprazole and its metabolites in human plasma; Effects of variuos experimental conditions and parameters, J. Liq. Chromatogr. R. T. 34 (2011) 1488 - 1501.

[25]. P.L. Garcia, E. Buffoni, F.P. Gomes, J.L.V. Quero, Analytical Method Validation, Wide Spectra of Quality Control. (2011) 
Table-1: Calibration range, linearity and sensitivity of the method

\begin{tabular}{lcc}
\hline \multirow{2}{*}{ Parameters } & \multicolumn{2}{c}{ Analytes } \\
\cline { 2 - 3 } & Domperidone & Itopride HCl \\
\hline Calibration range $(\mathrm{ng} / \mathrm{ml})$ & $10-600$ & $15-600$ \\
Linearity & & \\
Standard mixture & & \\
Regression equation & $\mathrm{y}=0.013 \mathrm{x}+0.017$ & $\mathrm{y}=0.007 \mathrm{x}+0.006$ \\
Correlation co efficient & 0.998 & 0.999 \\
Spiked plasma samples & & \\
Regression equation & $\mathrm{y}=0.011 \mathrm{x}+0.021$ & $\mathrm{y}=0.005 \mathrm{x}+0.001$ \\
Correlation co efficient & 0.997 & 0.996 \\
Sensitivity & & $12 \mathrm{ng} / \mathrm{ml}$ \\
Limit of detection (LOD) & $5 \mathrm{ng} / \mathrm{ml}$ & $15 \mathrm{ng} / \mathrm{ml}$ \\
Lower limit of quantification (LLOQ) & $10 \mathrm{ng} / \mathrm{ml}$ & \\
\hline
\end{tabular}


Table-2: Recovery and precision of the method

\begin{tabular}{|c|c|c|}
\hline \multirow{2}{*}{ Parameter } & \multicolumn{2}{|c|}{ Analytes } \\
\hline & Domperidone & Itopride $\mathrm{HCl}$ \\
\hline \multicolumn{3}{|l|}{ Recovery } \\
\hline Spiked conc. $(100 \mathrm{ng} / \mathrm{ml})$ & a $(91.26) ; 0.464$ & a $(89.82) ; 0.87$ \\
\hline Spiked conc. $(250 \mathrm{ng} / \mathrm{ml})$ & ${ }^{\mathrm{a}}(91.10) ; 0.958$ & a $(89.38) ; 1.22$ \\
\hline Spiked conc. $(500 \mathrm{ng} / \mathrm{ml})(\mathrm{n}=5)$ & ${ }^{\mathrm{a}}(92.31) ; 0.502$ & a $(89.78) ; 1.98$ \\
\hline \multicolumn{3}{|l|}{ Precision } \\
\hline \multicolumn{3}{|l|}{ Injection repeatability } \\
\hline Spiked conc. $(250 \mathrm{ng} / \mathrm{ml})$ & $\mathrm{b}_{32670 ; 1.28}$ & b24514; 1.097 \\
\hline Spiked conc. $(250 \mathrm{ng} / \mathrm{ml})(\mathrm{n}=5)$ & ${ }^{\mathrm{c}} 11.39 ; 1.15$ & ${ }^{c} 8.37 ; 0.764$ \\
\hline \multicolumn{3}{|l|}{ Analysis repeatability } \\
\hline Spiked conc. $(500 \mathrm{ng} / \mathrm{ml})(\mathrm{n}=5)$ & ${ }^{\mathrm{d}} 0.421 ; 3.8$ & ${ }^{\mathrm{d}} 0.40 ; 2.125$ \\
\hline \multicolumn{3}{|l|}{ Intermediate precision } \\
\hline \multicolumn{3}{|l|}{ Intraday reproducibility } \\
\hline Spiked conc. $(100 \mathrm{ng} / \mathrm{ml})$ & d91.18; 1.54 & d $83.95 ; 3.74$ \\
\hline Spiked conc. $(250 \mathrm{ng} / \mathrm{ml})$ & $\mathrm{d}_{2} 207.50 ; 2.71$ & ${ }^{\mathrm{d}} 199.12 ; 3.02$ \\
\hline Spiked conc. $(500 \mathrm{ng} / \mathrm{ml})(\mathrm{n}=5)$ & ${ }^{\mathrm{d}} 418.61 ; 3.19$ & ${ }^{d} 399.83 ; 2.76$ \\
\hline \multicolumn{3}{|l|}{ Inter day reproducibility } \\
\hline Spiked conc. $(100 \mathrm{ng} / \mathrm{ml})$ & ${ }^{\mathrm{d}} 89.54 ; 4.13$ & ${ }^{\mathrm{d}} 85.26 ; 4.58$ \\
\hline Spiked conc. $(250 \mathrm{ng} / \mathrm{ml})$ & ${ }^{\mathrm{d}} 209.26 ; 4.16$ & ${ }^{\mathrm{d}} 189.58 ; 3.97$ \\
\hline Spiked conc. $(500 \mathrm{ng} / \mathrm{ml})(\mathrm{n}=5)$ & ${ }^{\mathrm{d}} 411.59 ; 1.67$ & ${ }^{d} 395.30 ; 4.76$ \\
\hline
\end{tabular}

Results are presented as (mean); \%RSD

a: percent recovery; b: peak area; c: retention time; d: quantity recovered 
Table-3: Various pharmacokinetic parameters in healthy human volunteers following oral administration of fast dispersible tablets of Domperidone (10mg)

\begin{tabular}{lc}
\hline Parameter (Unit) & Results \\
\hline C max (ng/ml) & $24 \pm 6.01$ \\
T max (min) & $30 \pm 5.37$ \\
AUC (ng.hr/ml) & $168.7 \pm 19.33$ \\
$\mathrm{t}_{1 / 2}(\mathrm{hr})$ & $6.1 \pm 1.73$ \\
\hline
\end{tabular}

Results are presented as mean \pm S.D. $(n=6)$ 


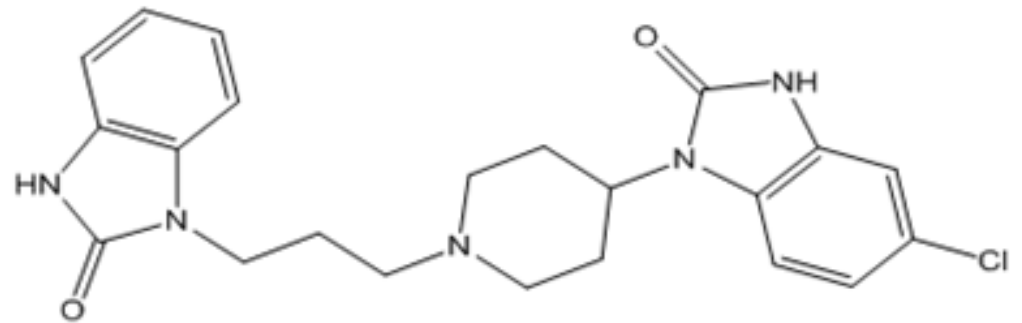

(A)

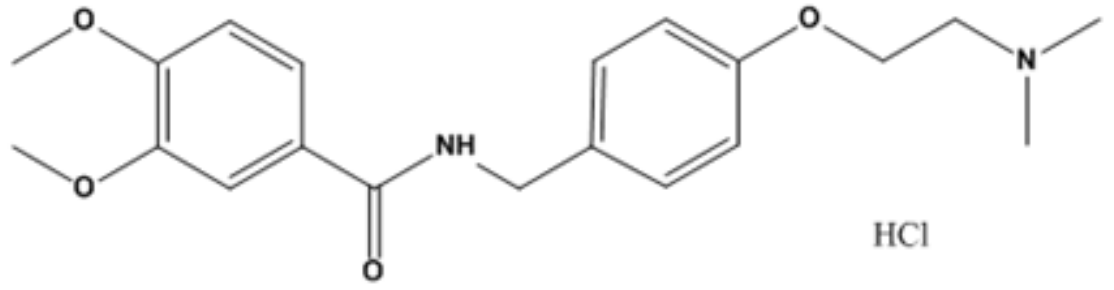

(B)

Figure-1: Chemical structures of; A) Domperidone, B) Itopride 


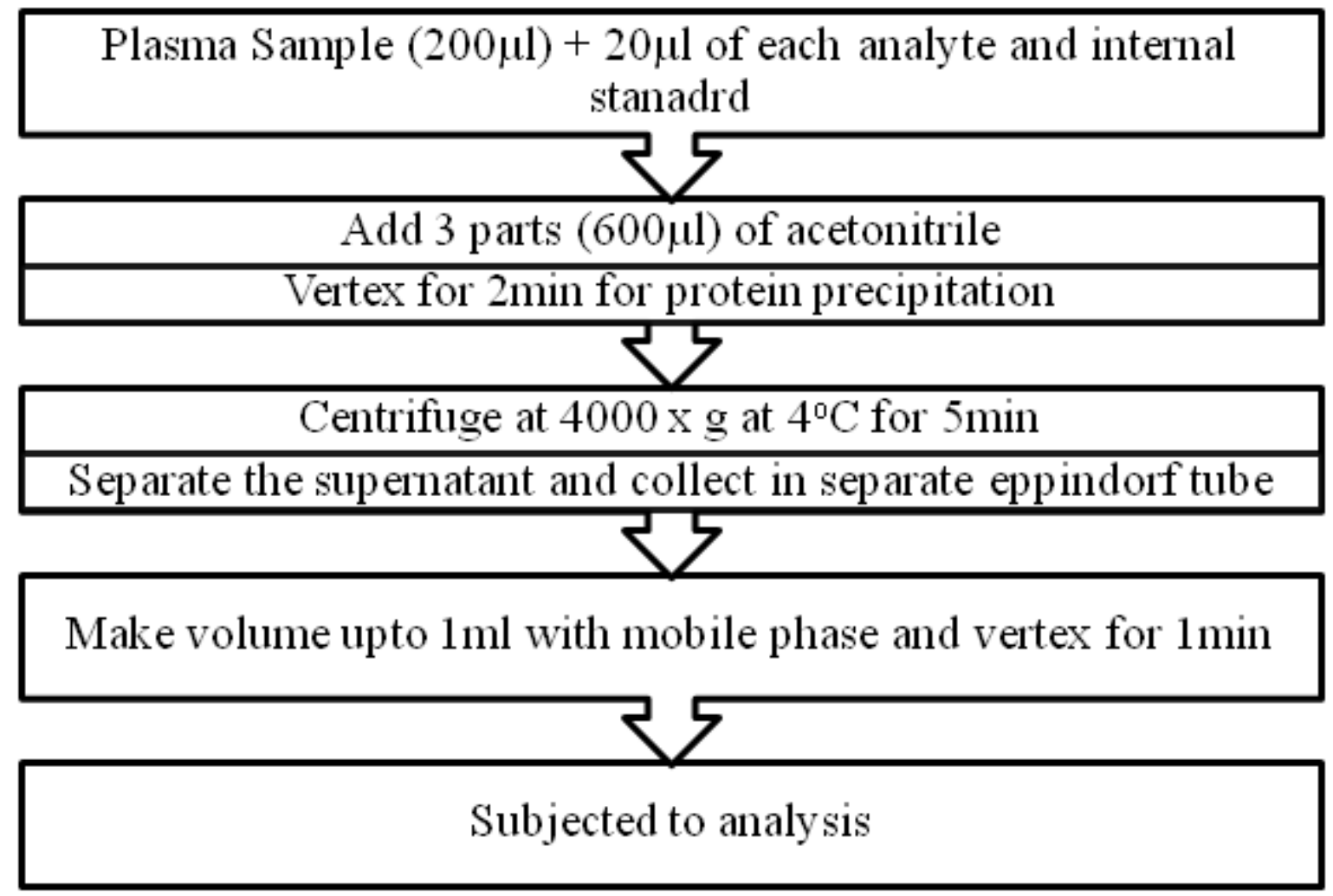

Figure-2: Extraction procedure of Domperidone and Itopride from human plasma 

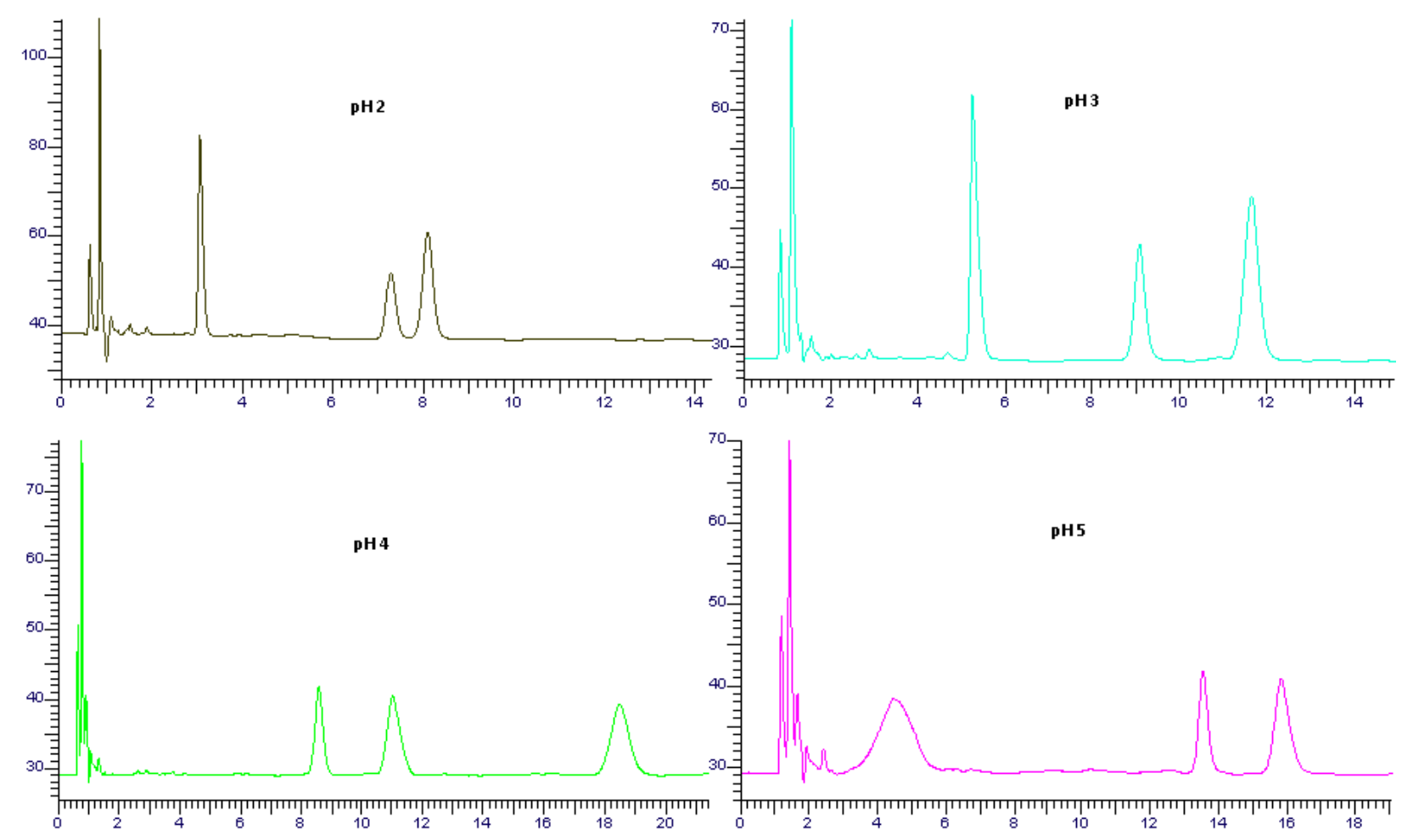

Figure-3: Effect of $\mathrm{pH}$ of mobile phase on various peak characteristics, Where 1) Internal Standard; 2) Itopride; 3) Domperidone 

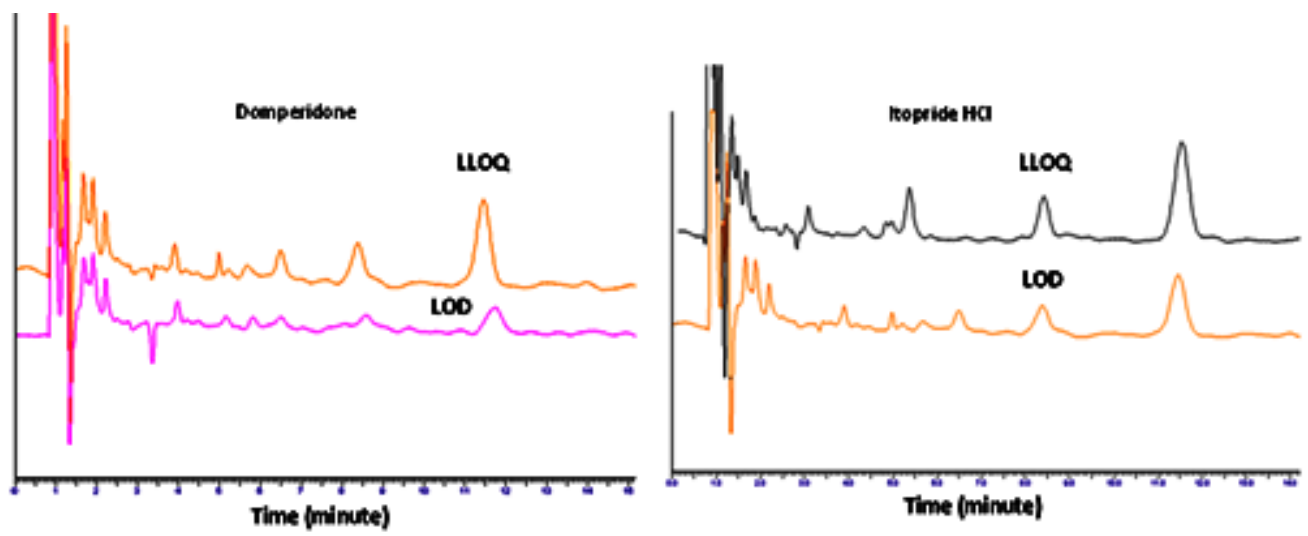

Figure-4: Chromatogram presenting lower limit of detection and lower limit of quantification of Domperidone and Itopride 


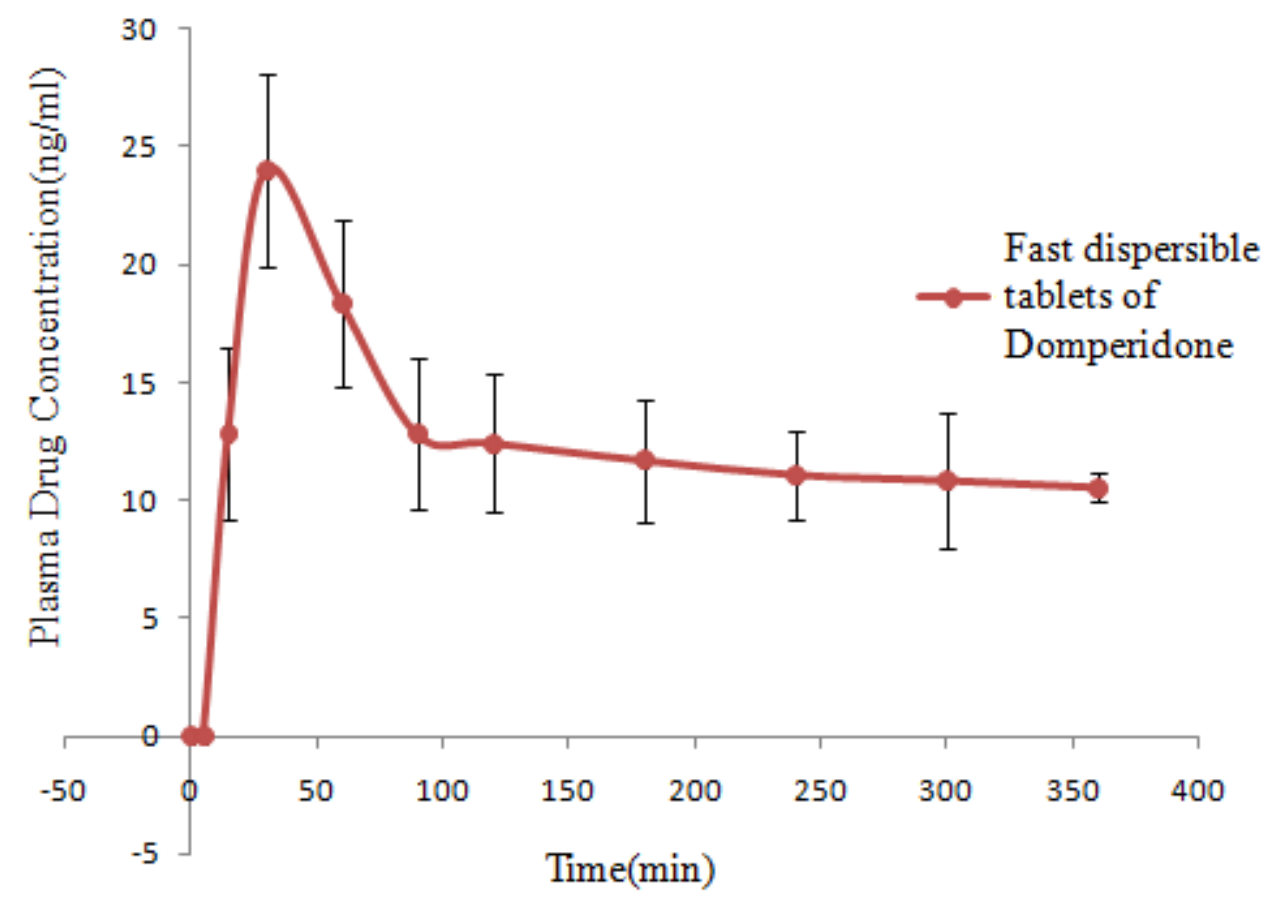

Figure-5: Plasma drug concentrations versus time curve for Domperidone given as fast dispersible tablets $(10 \mathrm{mg}$ ) single oral dose in healthy human volunteers (mean $\pm \mathrm{SD}, \mathrm{n}=6$ ) 